Arq. Bras. Med. Vet. Zootec., v.66, n.4, p.1179-1188, 2014

\title{
Avaliação genética de caprinos da raça Saanen nascidos no Brasil de 1979 a 2009
}

[Genetic evaluation of Saanen goats born in Brazil from 1979 to 2009]

\author{
T.A. Ferreira ${ }^{1}$, I.G. Pereira ${ }^{2}$, A.M.G. Gouveia ${ }^{2}$, A.V. Pires ${ }^{1}$, O. Facó ${ }^{3}$, M.M. Farah ${ }^{4}$, \\ M.C. Pessoa ${ }^{5}$, M.P.S.L.P.M. Guimarães \\ ${ }^{1}$ Faculdade de Ciências Agrárias - Universidade Federal dos Vales do \\ Jequitinhonha e Mucuri - Diamantina, MG \\ ${ }^{2}$ Escola de Veterinária - Universidade Federal de Minas Gerais - Belo Horizonte, MG \\ ${ }^{3}$ Embrapa Caprinos e Ovinos - Sobral, CE \\ ${ }^{4}$ Universidade Estadual Paulista - Jaboticabal, SP \\ ${ }^{5}$ Centro de Ciências Agrárias - Universidade Federal de Viçosa - Viçosa, MG \\ ${ }^{6}$ Associação de Criadores de Caprinos e Ovinos de Minas Gerais - Belo Horizonte, MG
}

\section{RESUMO}

O objetivo deste trabalho foi estimar herdabilidades, correlações genéticas e fenotípicas e tendências genéticas das características morfológicas e de tipo de caprinos da raça Saanen nascidos no Brasil de 1979 a 2009. Dados de 1243 caprinos, 197 machos e 1046 fêmeas, foram utilizados para estimar parâmetros genéticos e tendência das características: perímetro torácico, comprimento corporal, altura na cernelha, altura, largura e comprimento da garupa, bem como as principais características que definem o padrão racial e a aptidão do animal (paleta e linha superior, membros e pés, tipo leiteiro, capacidade de corpo, úbere, ligamento traseiro e dianteiro, textura do úbere, tetos e nota). Os componentes de variância foram estimados pelo método da máxima verossimilhança restrita em análise multicaracterística. A tendência genética foi obtida por meio da regressão dos valores genéticos médios por ano de nascimento. As estimativas de herdabilidade das características morfofuncionais variaram de 0,08 a 0,45 , as correlações genéticas de $-0,58$ a 0,89 e fenotípicas de $-0,11$ a 0,87 . A tendência foi de um leve declínio ao longo dos anos para a maior parte das características avaliadas, o que evidencia a existência de variabilidade genética aditiva entre os animais, mas demonstra que a seleção praticada tem sido pouco efetiva.

Palavras-chave: correlações genéticas, herdabilidade, morfologia, tendência genética

\begin{abstract}
The aim of this study was to estimate heritability, genetic and phenotypic correlations and genetic trends of morphological characteristics and type of Saanen goats born in Brazil from 1979 to 2009. Data from 1243 goats, 197 males and 1046 females were used to estimate genetic parameters and trends for the following traits: girth, body length, wither height, height, width and rump length, and the main traits that define the breed standard and ability of the animal (shoulder and topline, limbs and feet, dairy type, body capacity, mammary gland, linking front and rear, texture of the udder, teats and note). Variance components were estimated by Restricted Maximum Likelihood multi-trait analysis. Genetic trends were obtained by regression of mean breeding values by year of birth. The heritability estimates of morphological and functional traits ranged from 0.08 to 0.45 , the genetic correlations from -0.58 to 0.89 and phenotypes from -0.11 to 0.87. The trend was a slight decline over the years for most traits, which shows the existence of additive genetic variability among animals, but it demonstrates that the selection practiced has been ineffective.
\end{abstract}

Keywords: correlation, heritability, morphology, genetic tendency

Recebido em 8 de agosto de 2012

Aceito em 11 de março de 2014

E-mail: tatilitazoo@hotmail.com 


\section{INTRODUÇÃO}

O conhecimento sobre parâmetros genéticos e fenotípicos é imprescindível para a condução eficiente de qualquer programa de melhoramento animal. A predição dos valores genéticos dos animais depende da estimativa precisa da herdabilidade e das correlações genéticas para as características consideradas na seleção (Lôbo e Silva, 2005).

Na França, a seleção de caprinos leiteiros tem sido direcionada para melhorar a produção do conteúdo sólido do leite, de proteina e de gordura, com base principalmente em animais provindos de inseminação artificial (Bélichon et al., 2000). As tendências genéticas para essas características são positivas, e novas características complementares podem ser incluídas nos critérios de seleção, como sugerido por Manfredi et al. (2001), pois avaliações fenotípicas de tipo têm sido utilizadas em testes de progênie para selecionar reprodutores para produção de carne desde a década de 1960 . No Brasil, o sistema de classificação linear para caprinos é adotado pela maioria das associações de raças (ABCC, 2001), sendo empregado como critério de seleção pelos criadores com a finalidade de que as características desejáveis sejam transmitidas para seus descendentes.

Não existem ainda, no Brasil, teste de progênie oficial e trabalhos que considerem e ou estimem os parâmetros genéticos das características lineares de caprinos leiteiros. Assim, resta aos técnicos e produtores a necessidade de conhecer as relações existentes entre essas características lineares. As características de tipo para caprinos estudadas por Luo et al. (1997) mostram que principalmente as relacionadas ao úbere apresentaram valores de herdabilidade de moderados a altos, o que permite a seleção individual e um progresso genético mais rápido.

A fim de promover o melhoramento genético de caprinos leiteiros no Brasil, a Embrapa Caprinos e Ovinos em 2005, junto a outras entidades, implantou o Controle Leiteiro Oficial e criou o Arquivo Zootécnico Nacional (Facó et al., 2011).

A utilização de informações morfológicas e de tipo poderá contribuir com o programa de melhoramento genético de caprinos na elaboração dos índices de seleção para a espécie no Brasil, o que permitirá predizer o valor genético dos animais, conhecer o tamanho e o sentido das repostas correlacionadas, bem como o progresso alcançado.

Objetivou-se com este trabalho estimar as herdabilidades, as correlações genéticas e fenotípicas e as tendências genéticas das características morfológicas e de tipo de caprinos da raça Saanen nascidos no Brasil de 1979 a 2009.

\section{MATERIAL E MÉTODOS}

Para estimação dos parâmetros genéticos, da herdabilidade e das correlações genéticas e fenotípicas entre as medidas morfométricas e de tipo, foram utilizadas informações genealógicas e de morfologia existentes na Associação de Criadores de Caprinos e Ovinos de Minas Gerais- ACCOMIG/ Caprileite, num total de 1243 registros, sendo 197 machos e 1046 fêmeas da raça Saanen nascidos no Brasil de 1979 a 2009. As características morfométricas avaliadas foram: perímetro torácico, comprimento corporal, altura de cernelha, altura de garupa, largura da garupa, comprimento da garupa, bem como as principais características que definem o padrão racial e a aptidão do animal (paleta e linha superior, membros e pés, tipo leiteiro, capacidade de corpo, úbere, ligamento traseiro e dianteiro, textura do úbere, tetos e nota), em uma escala de 0 a 100 pontos. A característica cabeça não foi avaliada, em razão da sua redundância com a característica racial.

Todas as medidas corporais foram tomadas após o primeiro parto para as cabras e, para os bodes, após um ano de idade, para fins de obtenção do Registro Genealógico Definitivo (ABCC, 2001), e foram tomadas por técnicos credenciados pela Associação. As seguintes medidas foram determinadas com auxílio de fita métrica, com todos os animais em superfície plana: perímetro torácico (PT, circunferência externa do tórax, ao nível da cernelha), comprimento de corpo (CC, distância entre a parte cranial da tuberosidade maior do úmero à da tuberosidade isquiática), altura na cernelha (AC, altura no ponto mais alto da região interescapular), altura na garupa ( $\mathrm{AG}$, medida do solo à tuberosidade sacral do ílio, com os animais em superfície plana), largura de garupa (LG, distâncias entre as protuberâncias ilíacas) e comprimento de garupa (CG, distância 
entre a tuberosidade coxal do ílio e a tuberosidade isquiática). As características morfológicas ligadas à produção de leite foram avaliadas no momento da inspeção.

Foram formados grupos contemporâneos (GC) para remover vícios da avaliação genética em decorrência de efeitos ambientais diferenciais. Para formação dos GC, foram realizadas as análises de variância, a fim de se verificarem os efeitos fixos importantes a serem ajustados no modelo de avaliação genética, com uso do procedimento "General Linear Models" (GLM) do programa estatístico SAS (Statistical..., 2002). Os efeitos fixos significativos em análise de variância prévia utilizados na composição dos GC foram sexo, ano de nascimento do animal e estação do ano (chuvosa, de outubro a março/seca, de abril a setembro); o efeito fixo de criador foi considerado de forma separada com um total de 135 rebanhos. A separação ocorreu em razão da existência de poucos animais registrados por criatório, o que reduziu muito o número total de registros; quando este efeito fixo foi colocado separado, um número maior de animais foi, então, conservado. Classes de grupos contemporâneos que incluíam menos de três animais foram eliminadas, o que totalizou 63 GC. O efeito de técnico e idade do animal ao registro não foram considerados significativos. Para interpretação da herdabilidade, foram considerados baixos os valores de 0 a 0,15 ; entre 0,15 e 0,3, moderados; e acima de 0,3, considerou-se alta herdabilidade (Pereira, 2008).

Os componentes de (co)variância necessários à estimação dos parâmetros genéticos das características estudadas foram estimados pelo método da máxima verossimilhança restrita (REML) utilizando-se o software WOMBAT (Meyer, 2006).

O modelo animal considerado matricialmente é representado por:

$\mathrm{Y}=\mathrm{Xb}+\mathrm{Za}+\mathrm{e}$,

em que: y é o vetor de observações das características morfológicas e de tipo dos indivíduos; $\mathrm{X}$ é a matriz de incidência dos efeitos fixos; b é o vetor de efeitos fixos contendo grupo de contemporâneos e criador; $Z$ é a matriz diagonal de incidência dos valores genéticos; a é o vetor dos efeitos aleatórios genéticos aditivos; e é o vetor de efeito residual.
Admitiu-se que y tem distribuição normal multivariada, com vetor de médias

$$
\mu=\mathrm{E}(\mathrm{y})=\mathrm{Xb} \text {, }
$$

e que a esperança dos efeitos aleatórios são iguais a zero:

$$
\left[\begin{array}{c}
\mathrm{y} \\
\tilde{\mathrm{a}} \\
\tilde{\mathrm{e}} \\
\sim
\end{array}\right] \sim\left[\begin{array}{c}
\mathrm{Xb} \\
\phi \\
\phi
\end{array}\right],\left\{\left[\begin{array}{ccc}
\mathrm{ZGZ}+\mathrm{R} & \mathrm{ZG} & \mathrm{R} \\
\mathrm{GZ} & \mathrm{G} & \phi \\
\mathrm{R} & \phi & \mathrm{R}
\end{array}\right]\right\},
$$

A matriz de variâncias e covariâncias, para os efeitos aleatórios, é dada por:

$\operatorname{var}(\mathrm{Y})=\mathrm{ZGZ}+\mathrm{R}$

As matrizes $\mathrm{G}$ e $\mathrm{R}$ são dadas por:

$$
\begin{gathered}
\mathrm{G}=\mathrm{A} \otimes \mathrm{G}_{\mathrm{o}}=\mathrm{A} \otimes\left[\begin{array}{ccc}
\sigma_{\mathrm{G} 1}^{2} & \cdots & \sigma_{\mathrm{G} 1 \mathrm{n}} \\
\vdots & \ddots & \sigma_{\mathrm{G} 2 \mathrm{n}} \\
\sigma_{\mathrm{Gn} 1} & \sigma_{\mathrm{Gn} 2} & \sigma_{\mathrm{Gn}}^{2}
\end{array}\right] ; \\
\mathrm{R}=\mathrm{I} \otimes \mathrm{R}_{0}=\mathrm{I} \otimes\left[\begin{array}{ccc}
\sigma_{\mathrm{R} 1}^{2} & \cdots & \sigma_{\mathrm{R} 1 \mathrm{n}} \\
\vdots & \ddots & \sigma_{\mathrm{R} 2 \mathrm{n}} \\
\sigma_{\mathrm{Rn} 1} & \sigma_{\mathrm{Rn} 2} & \sigma_{\mathrm{Rn}}^{2}
\end{array}\right],
\end{gathered}
$$

em que: subscritos de 1 a $\mathrm{n}$ se referem às características avaliadas: $G_{\mathrm{o}}$, matriz de (co)variância genética aditiva; $\mathrm{R}_{\mathrm{o}}$, matriz de (co)variância residual; A, matriz dos coeficientes de parentesco de Wright entre os indivíduos; I, matriz identidade; $\otimes$, operador de produto direto.

A avaliação genética foi realizada por meio da predição dos valores genéticos pelo método da máxima verossimilhança restrita (REML) com o software WOMBAT.

A tendência genética foi obtida por meio da regressão dos valores genéticos médios por ano de nascimento.

\section{RESULTADOS E DISCUSSÃO}

Nenhuma das medidas morfométricas e de tipo tiveram uma grande dispersão (Tab. 1). Os valores médios observados para as características de conformação assemelham-se aos encontrados por Manfredi et al. (2001) e Mello e Schmidt (2008). 
Tabela 1. Resumo da estrutura de dados, número de animais (N), médias, desvios-padrão (DP) e coeficientes de variação $(\mathrm{CV} \%)$ das características morfológicas e de tipo de caprinos da raça Saanen nascidos no Brasil de 1979 a 2009

\begin{tabular}{lcccc}
\multicolumn{1}{c}{ Características } & $\mathrm{N}$ & Média & $\mathrm{DP}$ & $\mathrm{CV}(\%)$ \\
\hline Perímetro torácico (cm) & 1243 & 87,51 & 8,10 & 8,34 \\
Comprimento de corpo (cm) & 1243 & 78,56 & 7,60 & 8,55 \\
Altura na cernelha (cm) & 1243 & 73,54 & 5,81 & 6,59 \\
Altura na garupa (cm) & 1243 & 73,23 & 5,47 & 6,42 \\
Largura da garupa (cm) & 1243 & 14,66 & 4,25 & 27,62 \\
Comprimento da garupa (cm) & 1243 & 23,16 & 2,58 & 9,96 \\
Nota (pontos) & 1243 & 81,47 & 6,90 & 8,35 \\
Característica racial (pontos) & 1243 & 4,81 & 0,45 & 9,28 \\
Paleta e linha superior (pontos) & 1243 & 6,46 & 0,87 & 13,01 \\
Membros e pés (pontos) & 1243 & 9,29 & 1,32 & 14,01 \\
Tipo leiteiro (pontos) & 1243 & 16,62 & 1,76 & 10,44 \\
Capacidade corporal (pontos) & 1243 & 16,56 & 1,94 & 11,44 \\
Úbere (pontos) & 1046 & 7,23 & 1,21 & 16,24 \\
Ligamento traseiro (pontos) & 1046 & 4,11 & 0,83 & 18,87 \\
Ligamento dianteiro (pontos) & 1046 & 4,24 & 0,93 & 21,70 \\
Textura do úbere (pontos) & 1046 & 4,12 & 0,85 & 19,80 \\
Tetos (pontos) & 1046 & 3,06 & 0,78 & 25,09 \\
\hline
\end{tabular}

Somente largura da garupa, ligamento dianteiro e tetos apresentaram maior variabilidade entre os animais. As medidas de altura na cernelha e altura na garupa foram as que apresentaram maior homogeneidade. Isso mostra que a magnitude influencia não só a média, mas os desvios em relação a essa média. Pode-se ainda observar uma tendência de menor variabilidade para as características mensuradas objetivamente, medidas em centímetros, do que para aquelas tomadas subjetivamente, medidas por pontos. Exceções a esta regra seriam a largura de garupa, para as objetivas, nota e característica racial, para as subjetivas.

Os valores de herdabilidade estimados variam de baixos a altos, o que indica uma variabilidade genética aditiva considerável para algumas características e a existência de um potencial de resposta à seleção para morfologia e características que definem o tipo da raça (Tab. 2).

As medidas biométricas apresentaram herdabilidade de baixa a moderada. O valor estimado para perímetro torácico foi inferior ao de Luo et al. (1997), que relataram herdabilidade de 0,41, e ao de Manfredi et al. (2001), os quais observaram que essa característica parece estar negativamente associada à produção de leite. Segundo Yáñez et al., 2004, essa é a medida que melhor expressa a predição do peso vivo de cabritos.

Comprimento corporal e altura na garupa apresentaram herdabilidade moderada, o que pode ser explicado pela utilização de um número pequeno de reprodutores selecionados que apresentam essas características bem homogêneas, diminuindo, então, a variabilidade. A largura da garupa apresentou um valor moderado de herdabilidade, resultado significativo, pois essa característica está relacionada à reprodução, que geralmente apresenta valores de herdabilidade menores.

Característica racial apresentou herdabilidade moderada tendendo a alta, pois um animal, para ser registrado, tem que apresentar todos os critérios que definem a raça, o que reduz a heterogeneidade entre os animais. A característica membros e pés destacou-se como a maior herdabilidade de todas as características estimadas, resultado que aponta para a importância de uma boa abertura e de um bom posicionamento dos aprumos traseiros, que estão diretamente relacionados com uma melhor inserção do úbere e com a capacidade de caminhar do animal, sobretudo para aqueles que vão a pasto. Para essa mesma característica, Manfredi et al. (2001) encontraram herdabilidade baixa. 

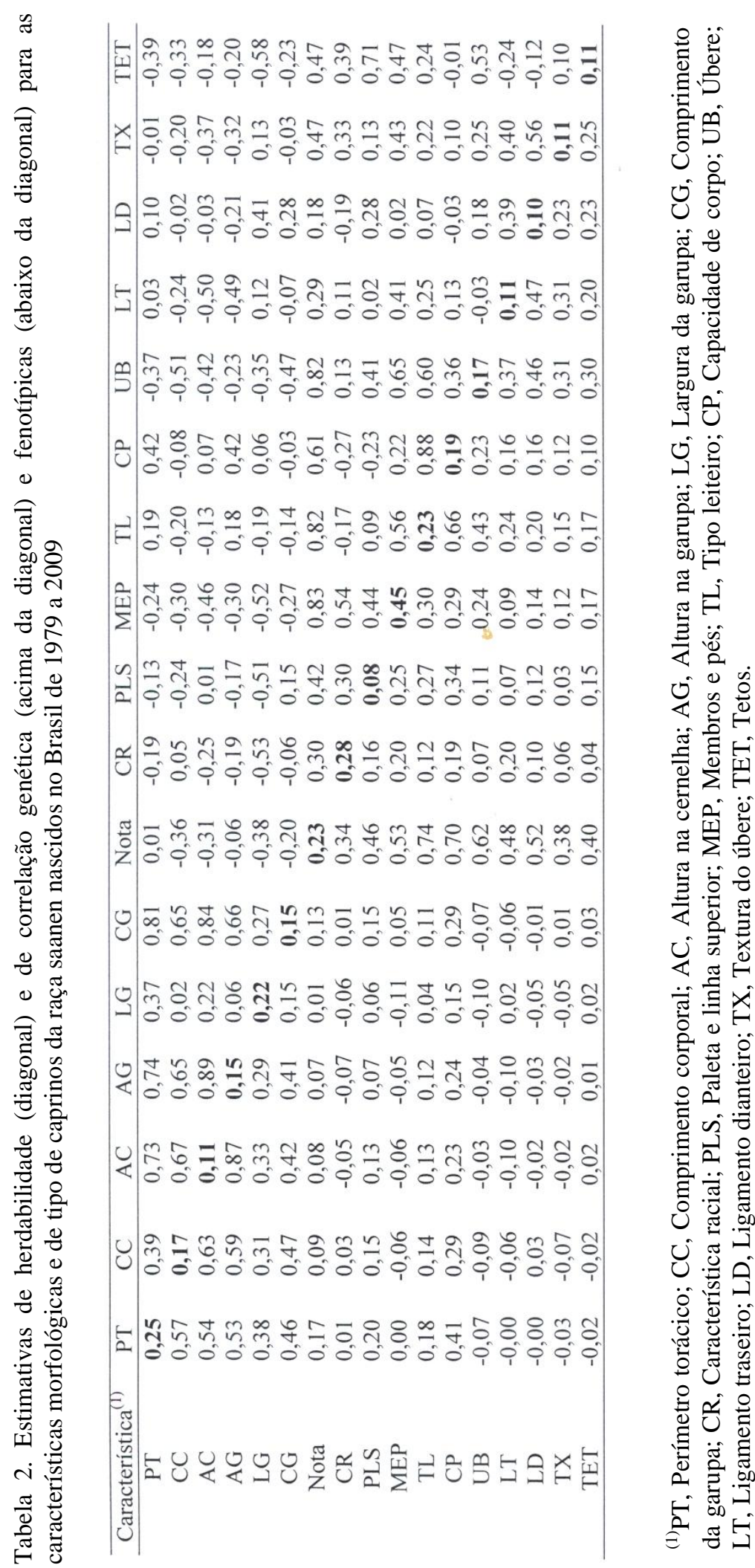
As características de escore ligadas ao úbere ou ao sistema mamário, importantes na seleção de cabras leiteiras, apresentaram estimativas de herdabilidade moderadas. Luo et al. (1997), em seu estudo sobre herdabilidades de características de tipo em caprinos, obtiveram para conjunto de úbere herdabilidade de 0,25 , valor maior ao encontrado neste estudo. As variáveis, tipo leiteiro e nota destacaram-se com o mesmo valor de herdabilidade moderada, o que aponta ser a classificação final um resumo das características que definem o tipo dos caprinos leiteiros e indica também uma influência parcial do ambiente sobre elas. Todavia, há necessidade de avaliar a correlação genética entre estas e a produção de leite. A herdabilidade para capacidade corporal demonstra moderada variabilidade genética, mas foi inferior à relatada por Luo et al. (1997), que estimaram herdabilidade de 0,27 para escore final em caprinos.

As correlações genéticas entre as características morformétricas e de tipo se caracterizaram de baixas a altas (Tab. 2), destacando-se altura na cernelha e na garupa e entre comprimento da garupa e altura na cernelha. Dessa forma, podese afirmar que, quando duas características apresentam correlação altamente positiva, a ênfase na seleção deverá ser em apenas uma, para o melhoramento de ambas, reduzindo-se o número de características a serem selecionadas. Largura da garupa e dos tetos demonstrou uma correlação negativa moderada, com base em que se pode inferir que, à medida que aumenta a largura da garupa, o posicionamento ideal para os tetos fica comprometido.

A nota final do animal apresentou alta correlação com membros e pés, tipo leiteiro e úbere, o que mostra que a boa classificação do caprino está altamente relacionada a um melhor desempenho da função produtiva e a interesse econômico. Selecionar um bom animal para capacidade corporal significa dizer que ele também apresenta um bom desenvolvimento leiteiro devido à alta correlação existente. Nota-se, ainda, que a variável tipo leiteiro apresenta correlações moderadas com tendência a altas para as características que compõem o conjunto de úbere. Resultados semelhantes foram encontrados por Luo et al. (1997) para escore final e características do úbere $(0,66)$. Correlação moderada para úbere e tetos foram estimadas, semelhantemente a Manfredi et al. (2001), que também encontraram efeito significativo do escore do ubere na produção de leite, justificando, assim, a inclusão de algumas características de úbere na lista dos critérios de seleção, com o objetivo de selecionar indivíduos capazes de suportar altos níveis de produção de leite.

Para as correlações fenotípicas entre as características morfológicas e de tipo para a raça Saanen, observa-se, pela Tab. 2, que elas foram, em sua maioria, de moderadas a altas. Novamente as correlações fenotípicas entre altura na cernelha e altura na garupa foram elevadas. Nota, tipo leiteiro e capacidade corporal apresentaram também valores altos, e essas características se correlacionam moderadamente com as variáveis do conjunto que compõe o úbere, o que mostra a probabilidade de essas características serem afetadas pelos mesmos genes, podendo, então, ser reduzido o número de variáveis a serem analisadas.

Com base em uma seleção fenotípica associada a uma seleção por pedigree, percebe-se, por meio dos gráficos, uma tendência ao declínio para as medidas perímetro torácico $\left(-2,01 \mathrm{~cm} \mathrm{ano}^{-1}\right)$ comprimento de corpo $\left(-0,59 \mathrm{~cm} \mathrm{ano}^{-1}\right)$ altura na garupa $\left(-0,58 \mathrm{~cm}^{2} \mathrm{ano}^{-1}\right)$, e uma tendência para o acréscimo de altura na cernelha $\left(1,52 \mathrm{~cm} \mathrm{ano}^{-1}\right)$, largura da garupa $\left(0,89 \mathrm{~cm} \mathrm{ano}^{-1}\right)$ e comprimento da garupa $\left(0,50 \mathrm{~cm} \mathrm{ano}^{-1}\right)($ Fig. 1). A redução de algumas características, como perímetro torácico, merece atenção, pois pode acarretar uma baixa capacidade torácica, que está ligada à aclimatação e ao potencial respiratório do animal. 

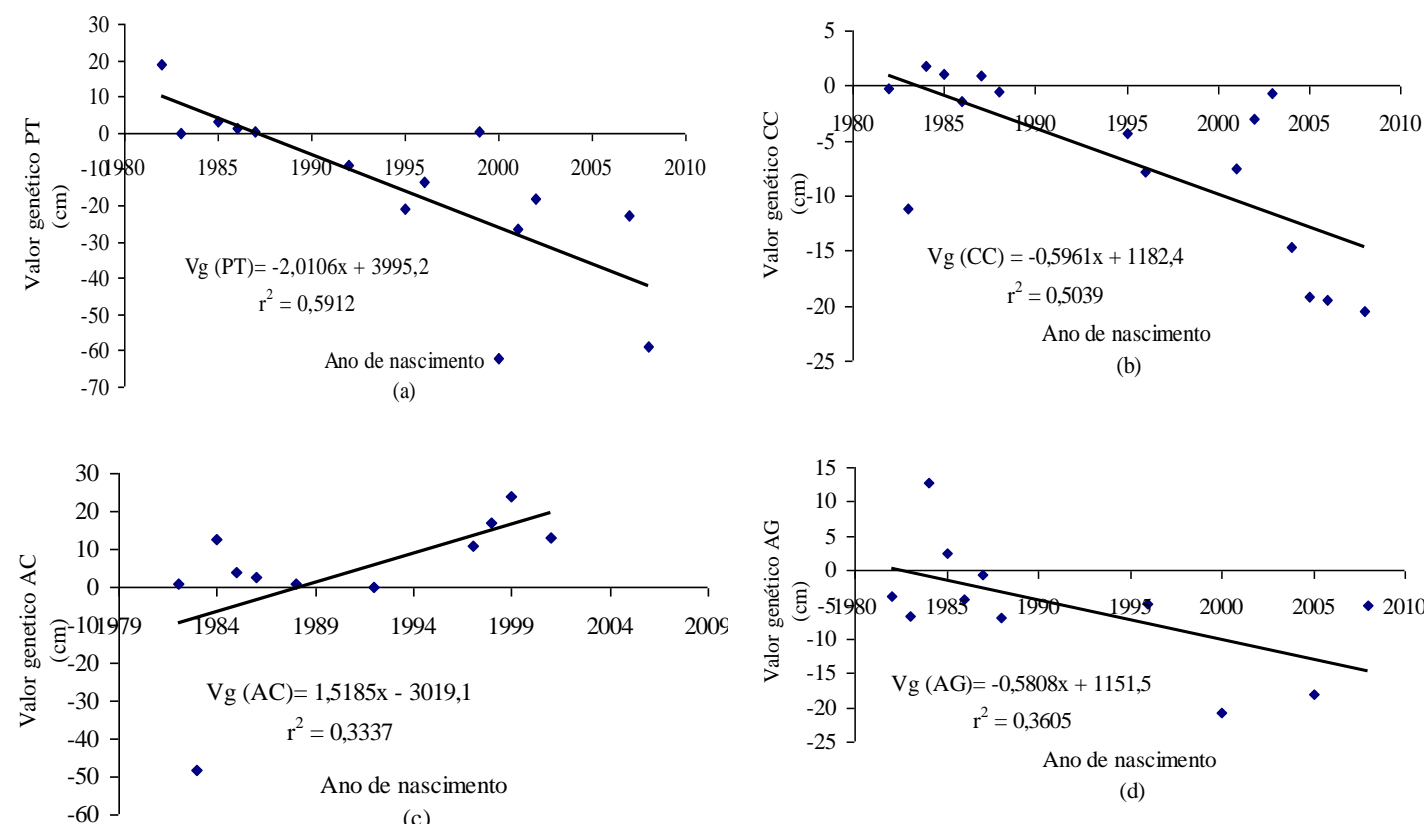

(c)

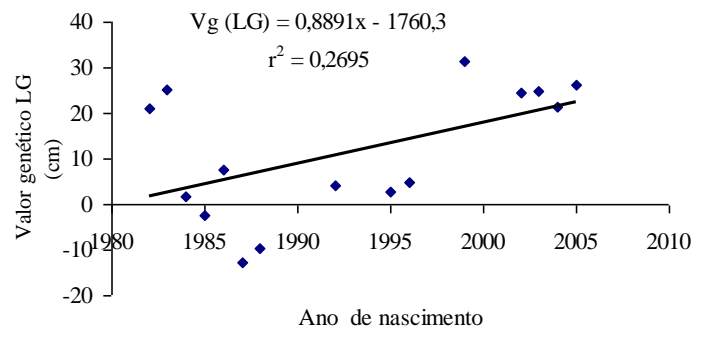

(e)

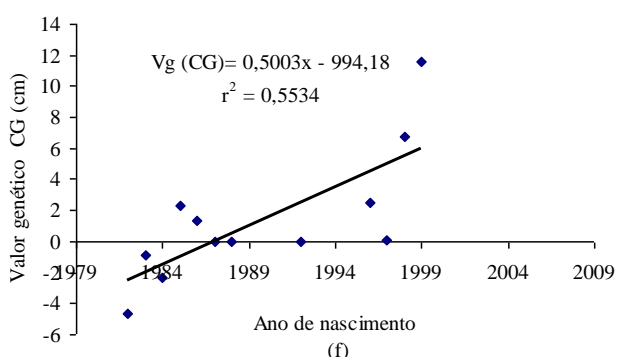

(f)

Figura 1. Tendência genética do valor genético para perímetro torácico (a), comprimento corporal (b), altura na cernelha (c), altura na garupa (d), largura da garupa (e) e comprimento da garupa (f) em caprinos da raça Saanen nascidos no período de 1979 a 2009.

Nota e capacidade de corpo apresentaram tendência ao aumento, respectivamente $(1,32$ ponto ano $^{-1}$ e 0,30 ponto ano ${ }^{-1}$ ), e as variáveis característica racial e paletas e linha superior apresentaram-se, respectivamente, de forma inalterada $\left(-0,0013\right.$ ponto ano ${ }^{-1}$ e $-0,0017$ ponto $\left.\mathrm{ano}^{-1}\right)$. Foi assinalada uma tendência ao declínio para membros e pés $\left(-0,18\right.$ ponto $\left.\mathrm{ano}^{-1}\right)$, indicador de que os animais possam estar com os membros mais frágeis, o que compromete a sua locomoção. Isso tem ocorrido porque a seleção, muitas vezes, é baseada apenas no volume de leite produzido, conduta que relega a segundo plano as outras características que são essenciais para garantir a longevidade do animal. Uma tendência ao aumento ocorreu na característica ligada ao tipo leiteiro $\left(0,33\right.$ ponto ano $\left.{ }^{-1}\right)$, que está diretamente ligada à função produtiva do animal (Fig. 2). 


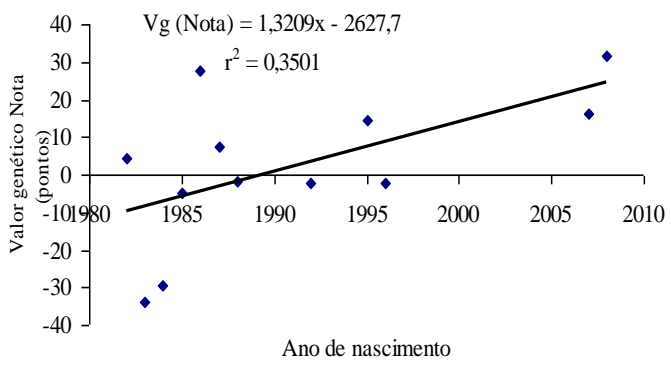

(g)

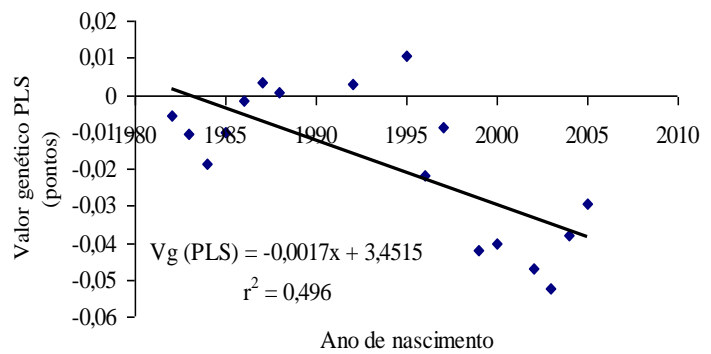

(i)

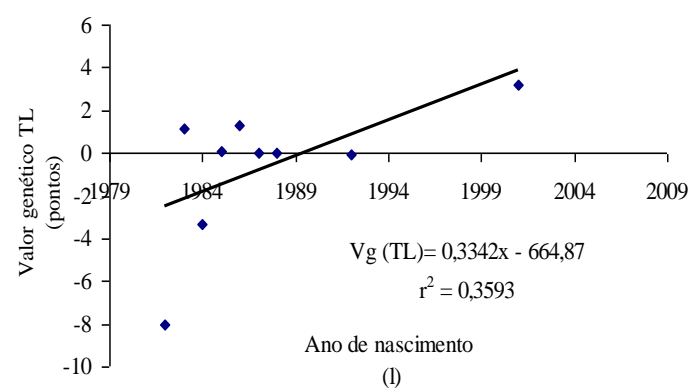

(l)

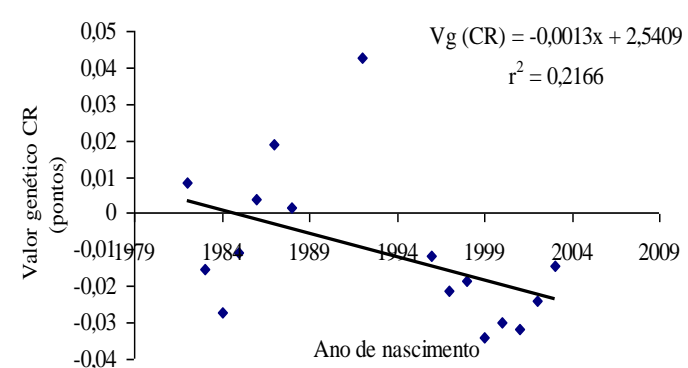

(h)
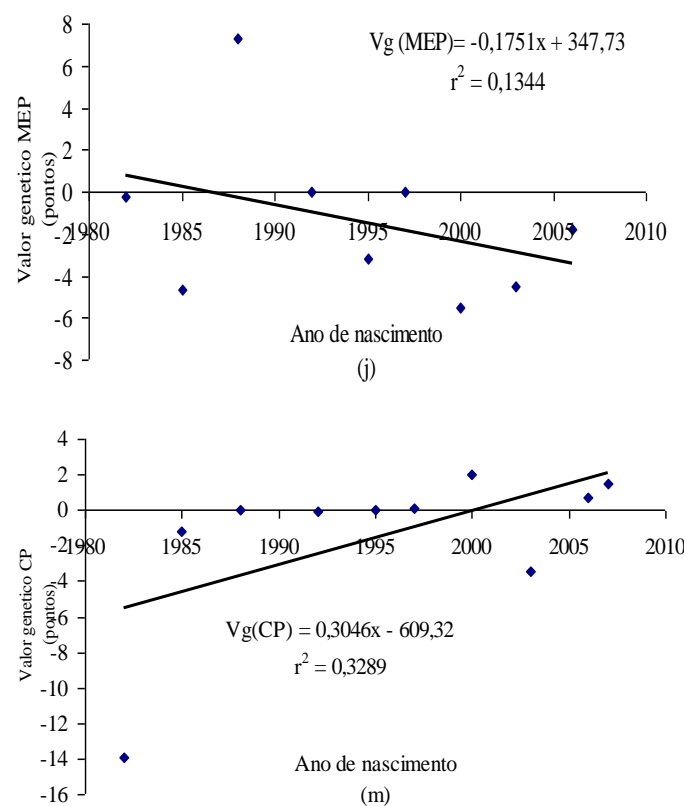

Figura 2. Tendência genética do valor genético para nota final (g), característica racial (h), paleta e linha superior (i), membros e pés (j), tipo leiteiro (l) e capacidade de corpo (m) em caprinos da raça Saanen nascidos no período de 1979 a 2009.

Conjunto de úbere apresentou tendência à queda ao longo dos anos $\left(-0,02\right.$ ponto $\left.\mathrm{ano}^{-1}\right)$. As tendências para variáveis ligamento traseiro, ligamento dianteiro, textura e tetos apresentaramse, respectivamente, de forma inalterada $(0,0012$ ponto ano $\left.{ }^{-1}\right),\left(-0,001\right.$ ponto ano $\left.{ }^{-1}\right),(0,0009$ ponto ano $\left.^{-1}\right)$ e $\left(-0,001\right.$ ponto ano $\left.{ }^{-1}\right)$ (Fig. 3).
As tendências genéticas ao longo dos anos foram discretas para a maior parte das características avaliadas, o que demonstra que a seleção que vem sendo praticada tem tido pouca efetividade, talvez pela multiplicidade de critérios, mas principalmente pela falta de uma melhor definição dos objetivos e critérios de seleção. 

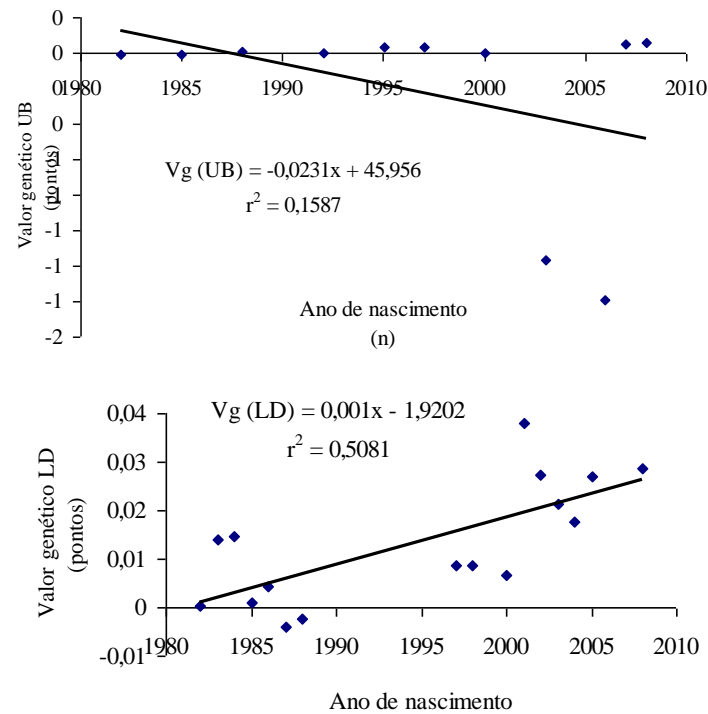

(p)

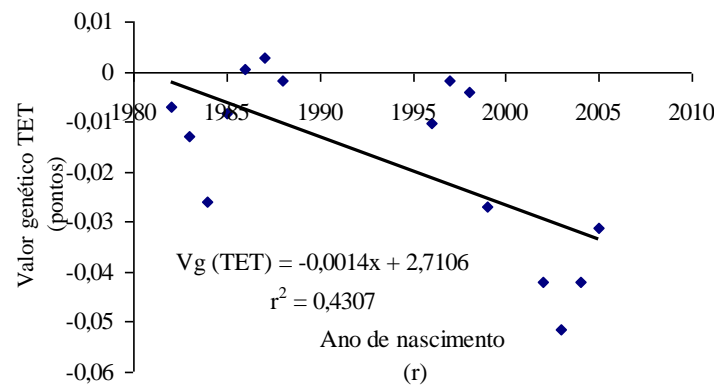

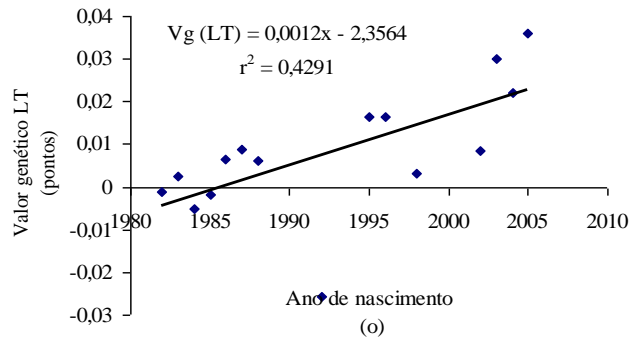

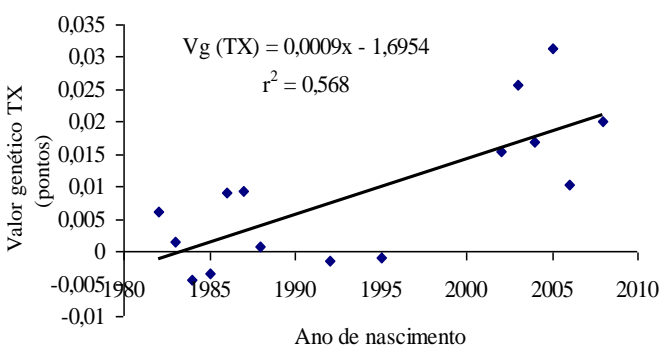

(q)

Figura 3. Tendência genética do valor genético para úbere (n), ligamento traseiro (o), ligamento dianteiro (p), textura do úbere (q) e tetos (r) em caprinos da raça Saanen nascidos no período de 1979 a 2009.

\section{CONCLUSÕES}

As estimativas de herdabilidade apresentam magnitudes variáveis, o que evidencia a existência de variabilidade genética aditiva entre os animais para algumas características. $\mathrm{Na}$ maioria das características, as correlações genéticas apresentam valores de moderados a altos, o que demonstra a possibilidade de resposta correlacionada.

\section{AGRADECIMENTOS}

À Caprileite/Associação dos Criadores de Caprinos e Ovinos de Minas Gerais (ACCOMIG), pela disponibilização dos dados para realização deste trabalho e a FAPEMIG pelo apoio financeiro.

\section{REFERÊNCIAS}

ABCC, Associação Brasileira dos Criadores de Caprinos. Regulamento do serviço de registros genealógico das raças caprinas, Aprovado pelo Ministério da Agricultura em 26/09/2001. Disponível em: <http://www.caprileite.com.br>. Acessado em: 10 jul. 2011.

BÉLICHON, S.; MANFREDI, E.; PIACÉRE, A. Genetic parameters of dairy traits in the Alpine and Saanen goat breeds. Genet. Sel. Evol., v.30, p.529-534, 2000.

FACÓ, O.; LÔBO, R.N.B.; GOUVEIA, A.M.G. et al. Breeding plan for commercial dairy goat production systems in southern Brazil. Small Rumin. Res., v.98, p.164-169, 2011. 
LÔBO， R.N.B.; SILVA， F.L.R. Parâmetros genéticos para Características de interesse econômico em cabras das raças Saanen e Anglonubiana. Rev. Cienc. Agro., v.36, p.104-110, 2005.

LUO, M.F.; WIGGANS, G.R.; HUBBARD, S.M. Variance component estimation and multitrait genetic evaluation for type traits of dairy goats. J. Dairy Sci., v.80, p.594-600, 1997.

MANFREDI, E.; PIACERE, A.; LAHAYE, P. et al. Genetic parameters of type appraisal in Saanen and Alpine goats. Livest. Prod. Sci., v.70, p.183-189, 2001.

MELLO, F.A.; SCHMIDT, V. Caracterização biométrica de caprinos Anglo-nubianos nascidos no Brasil, no período de 1993 a 2001. Arch. Zootec., v.57, p.525-535, 2008.
MEYER, K. WOMBAT: a program for mixed model analyses by restricted maximum likelihood. Users note: Animal Genetics and Breeding Unit. Armidale, 2006.

PEREIRA, J.C.C. Melhoramento genético aplicado à produção animal. 5.ed. Belo Horizonte: FEPMVZ, 2008. 618p.

STATISTICAL analysis system - SAS User's Guide. Cary: 2002.

YÁÑEZ, E.A.; RESENDE, K.T.; FERREIRA, A.C.D. et al. Utilização de medidas biométricas para predizer características da carcaça de cabritos Saanen. Rev. Bras. Zootec., v.33, p.1564-1572, 2004. 